\title{
Current and future conditions of stroke care in Brazil
}

\author{
Condições atuais e futuras do atendimento do acidente vascular cerebral no Brasil \\ Vivian Dias Baptista Gagliardi1,2, Rubens Jose Gagliardi1,3
}

Regarding Dr. Pacheco and Dr. Rocha's statement ${ }^{1}$ that future conditions of care for stroke patients in Brazil may worsen, given the need for implementation and updating of stroke centers, we acknowledge that this could be true if our Brazilian Stroke Society was not taking the necessary measures, but there has been great effort in improving this scenario. There has been an effort by specialized neurologists to improve care and teach the population to recognize the signs of stroke and to seek care as soon as possible ${ }^{2}$, as well as efforts from the stroke organizations to improve the conditions of stroke care ${ }^{3}$.

The establishment of several multiprofessional and properly-trained stroke teams all over the country is a challenge that we hope will be achieved. Undoubtedly, the presence of the neuroradiologist and the neurointerventionist are fundamental in this team for neurointerventional treatment, which has shown excellent results when appropriately indicated and conducted ${ }^{4,5,6}$. In our setting, there is a very large ongoing study entitled RESILIENT (EndoVascular Treatment with Stentretriever and/or Thromboaspiration vs. Best Medical Therapy in Acute Ischemic Stroke - ClinicalTrials.gov identifier [NCT number: NCT02216643]), led by Dr. Sheila Martins, that will evaluate the feasibility of mechanical thrombectomy in properly-selected patients in the Brazilian public health setting.
Non-contrast head computed tomography is very useful for patients who arrive at the hospital within 4.5 hours of the stroke because it allows the use of chemical thrombolysis $^{7}$, which has good results, and should be the method to start treatment. Complex cases that could benefit from neurointerventional therapy can benefit from the "drip-and-ship" treatment model ${ }^{8}$, which consists of transporting patients who do not respond to chemical thrombolysis, or who are identified as being able to benefit from endovascular treatment, to another facility that can provide it; it is a safe and feasible alternative to ensure that all patients have access to appropriate treatment. Another alternative would be to improve the prehospital triage, referring all stroke patients to specific stroke centers that have the structure to provide adequate treatment, including neurointerventional treatment if needed (the "mothership" model $)^{9}$. These actions could aid in improving the allocation of resources for the treatment of stroke.

Our study ${ }^{10}$ aimed at analyzing the current care situation in Brazil through the evaluation of neurologists, pointing out the difficulties and limitations, contributing to the detection of failures and trying to find solutions, which consist of improving the knowledge of the disease in the population, better medical training and greater and better funding and government support.

\section{References}

\footnotetext{
1. Pacheco FT, Rocha AJ. Stroke care conditions in Brazil: can it still get worse?Arq Neuropsiquiatr 2019;77(1):66-67. https://doi.org/10.1590/0004-282X20180145

2. Gomes AB, Henrique M Jr, Schoeps VA, Santos MM, Pellegrinelli A, Matos BP, et al. Popular stroke knowledge in Brazil: a multicenter survey during “World Stroke Day”. eNeurologicalSci. 2016 Dec;6:63-7. https://doi.org/10.1016/j.ensci.2016.12.002

3. Ministério da Saúde (BR). Brasil e mais onze países assinam documento para prevenção e enfretamento do AVC. Brasília, DF,
}

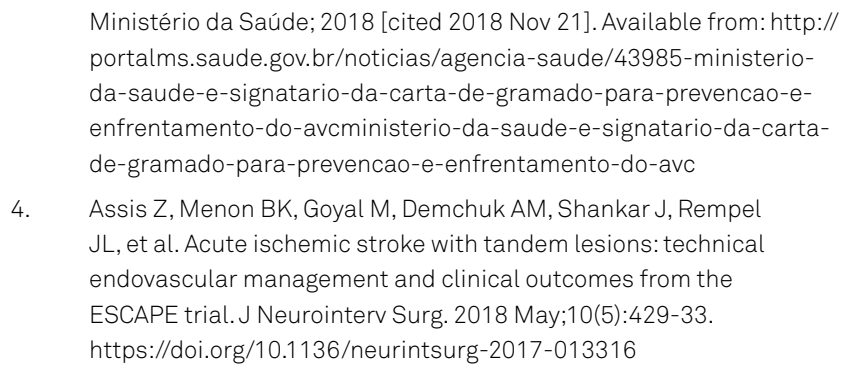

Ministério da Saúde; 2018 [cited 2018 Nov 21]. Available from: http:// portalms.saude.gov.br/noticias/agencia-saude/43985-ministerioda-saude-e-signatario-da-carta-de-gramado-para-prevencao-eenfrentamento-do-avcministerio-da-saude-e-signatario-da-cartade-gramado-para-prevencao-e-enfrentamento-do-avc

4. Assis Z, Menon BK, Goyal M, Demchuk AM, Shankar J, Rempel $\mathrm{JL}$, et al. Acute ischemic stroke with tandem lesions: technical endovascular management and clinical outcomes from the ESCAPE trial.J Neurointerv Surg. 2018 May;10(5):429-33. https://doi.org/10.1136/neurintsurg-2017-013316

\footnotetext{
1'Irmandade da Santa Casa de São Paulo, Disciplina de Neurologia, São Paulo SP, Brasil;

${ }^{2}$ Universidade Federal de São Paulo, Departamento de Neurologia e Neurocirurgia, São Paulo SP, Brasil;

${ }^{3}$ Faculdade de Ciências Médicas da Santa Casa de São Paulo, São Paulo SP, Brasil.

Vivian Dias Baptista Gagliardi (iD) https://orcid.org/0000-0003-3182-5147

Correspondence: Vivian Dias Baptista Gagliardi; Rua Dr. Motta Junior 112; 01221-020 São Paulo SP, Brasil; E-mail: viviandbg@gmail.com

Conflict of interest: There is no conflict of interest to declare.

Received 14 December 2018; Accepted 21 December 2018.
} 
5. Saver JL, Goyal M, Bonafe A, Diener HC, Levy EI, Pereira VM, et al. Solitaire ${ }^{\mathrm{TM}}$ with the Intention for Thrombectomy as Primary Endovascular Treatment for Acute Ischemic Stroke (SWIFT PRIME) trial: protocol for a randomized, controlled, multicenter study comparing the Solitaire revascularization device with IV tPA with IV tPA alone in acute ischemic stroke. Int J Stroke. 2015 Apr;10(3):439-48. https://doi.org/10.1111/ijs.12459

6. Broderick JP, Berkhemer OA, Palesch YY, Dippel DW, Foster LD, Roos YB, et al. Endovascular therapy is effective and safe for patients with severe ischemic stroke: pooled analysis of interventional management of stroke III and multicenter randomized clinical trial of endovascular therapy for acute ischemic stroke in the netherlands data. Stroke. 2015 Dec;46(12):3416-22. https://doi.org/10.1161/STROKEAHA.115.011397
7. Martins SC, Freitas GR, Pontes-Neto OM, Pieri A, Moro CH, Jesus PA, et al. Guidelines for acute ischemic stroke treatment: part II: stroke treatment. Arq Neuropsiquiatr. 2012 Nov;70(11):885-93. https://doi.org/10.1590/S0004-282X2012001100012

8. Deguchi I, Mizuno S, Kohyama S, Tanahashi N, Takao M. Drip-and-ship thrombolytic therapy for acute ischemic stroke. J Stroke Cerebrovasc Dis. 2018 Jan;27(1):61-7. https://doi.org/10.1016/j.jstrokecerebrovasdis.2017.07.033

9. Ismail M, Armoiry X, Tau N, Zhu F, Sadeh-Gonik U, Piotin M, et al. Mothership versus drip and ship for thrombectomy in patients who had an acute stroke: a systematic review and meta-analysis.J Neurointerv Surg. 2019 Jan;11(1):14-9. https://doi.org/10.1136/neurintsurg-2018-014249

10. Gagliardi VD, Simis M, Cabeça HL, Gagliardi RJ. Medical perception of stroke care conditions in Brazil. Arq Neuropsiquiatr. 2018 Jan;76(1):13-21. https://doi.org/10.1590/0004-282×20170178 